\title{
Investigation of Institutional Changes in the UK Housing Market using Structural Break Tests and Time Varying Parameter Models
}

\author{
Hanxiong Zhang, Robert Hudson, Hugh Metcalf, Viktor Manahov
}

\begin{abstract}
This paper investigates the effects of institutional changes within the UK housing market in recent decades using structural break tests and time varying parameter models. This approach is motivated by models of institutional change drawn from the political science literature which focus on the existence of both fast moving and slow moving institutional changes and the interactions between them as drivers of the dynamics of asset prices. As a methodological contribution we use several time varying parameter models for the first time in investigations of institutional change. Our findings support the existence of both structural breaks and continuous variance in parameters. This contributes to our understanding of the housing market in two respects. Firstly, the dates of structural breaks appear to better match unexpected market shocks rather than remarkable political events and this supports prior institutional theory. Secondly, assessment of the effect of slow-moving institutional changes shows that people's biased expectations rather than the economic fundamentals, have increasingly played an important role in driving housing prices in the short-run although fundamentals continue to drive house prices to converge to their long-run equilibrium.
\end{abstract}

JEL Classification: C32; G00; G02; G12; G17.

Keywords: Institutional Changes, Time Varying Parameters, Bubbles, Housing Market.

\section{Introduction}

In the UK, in the period since the 1980 s there have been remarkable political reforms, such as 
financial deregulation and liberalization; and technology advances, such as mortgage securitization. Given these changes a large number of papers claim there have been major institutional changes in the UK housing market (Baddeley 2005; Brown et al. 1997). Unfortunately, to date, there is hardly any comprehensive empirical evidence available to support these claims. This paper empirically investigates the nature of institutional changes within the UK housing market using structural break tests and time varying parameter models.

We draw our models of institutional change from the political science and development literature and consider an institutional change as being a change in the rules of the economy. There are two forms of institutional changes (Culpepper 2005; Roland 2004). Fast-moving (or formal) institutions, such as political and/or legal systems, do not necessarily change frequently but can change very rapidly, even overnight. Political and/or legal reform is often a necessary but insufficient condition for statistically significant fast-moving institutional changes, given that people's shared beliefs can persist even after changing the laws. Slowmoving (or informal) institutions, are related to culture and include values, beliefs and social norms. The development of technology and scientific knowledge drives the evolution of culture. Slow-moving institutions change continuously, which produces inconsistencies with fast-moving institutions which, in turn, create pressures for fast changes. It is the interaction between slow-moving institutions and fast-moving institutions that drive the institutional changes which, in turn, drives the dynamics of asset prices.

The forgoing models of institutional change inform our empirical work and particularly our use of structural break tests and time varying parameter models. From an empirical viewpoint, statistically significant structural breaks will indicate fast-moving institutional changes. Even though sophisticated structural break tests may detect all structural break points, they are, however, naturally unsuitable to investigate the slow-moving institutional 
changes. For this purpose, a more natural model is one in which parameters gradually change over time with small, Gaussian shifts, rather than rare but large 'structural break' shifts. The slow-moving institutional changes are identified as occurring if the coefficients in a regression are time varying (Baddeley 2005; Brown et al. 1997; Culpepper 2005; Roland 2004; Guirguis et al. 2005; Hansen 2001; Pesaran and Timmermann 2002). There are several other good reasons for using the time varying parameter models in economic modeling (Brown et al. 1997; Engle and Watson 1987; Guirguis et al. 2005). Initially, the Lucas (1976) critique proposes a behavioral motivation for parameter variation. Lucas (1976) suggests people adjust not only their behavior in response to new policies, but also their expectations of the economic model believed relevant to existing policies. Secondly, changes in the unobservable components of economic variables, such as expectations, will drive institutional changes in the data generating process. Thirdly, model mis-specification is another source of time varying parameters given it is generally impossible to perfectly specify an economic data generating process.

Our work expands on the existing methodology literature by using three Kalman filteringbased Time Varying Parameter (TVP) models to quantify the slow-moving institutional changes in the UK housing market. The TVP models usually take the state space specification and are estimated by the Kalman filter algorithm (Brown et al. 1997; Guirguis et al. 2005; Zivot and Wang 2006). The three TVP models are the Time Varying Parameter with Principal Component Analysis (TVP-PCA), Time Varying Parameter with Principal Component Analysis and Bubbles (TVP-PCA-Bubble), and Time Varying Parameter with Error Correction Model (TVP-ECM). Papers in the literature have often used TVP-PCA and TVP-ECM in dynamic forecasting (Li et al. 2006; Stock and Watson 2006). However, we are not aware of any studies in the literature investigating institutional changes using the three aforementioned TVP models. Principal Component Analysis (PCA) investigates the dynamic 
links among observed, correlated economic variables by using a potentially lower number of unobservable common factors. Relative to the TVP-PCA, the TVP-PCA-Bubble incorporates housing bubbles as an additional independent variable, which controls for people's biased expectations. One of the advantages of the Error Correction Model (ECM) lies in its ability to capture the short-run dynamic self-correcting process of the housing market toward its longrun equilibrium relationship ( $\mathrm{Li}$ et al. 2006). Moreover, ECM and PCA can eliminate the occurrence of spurious regression and multicollinearity problems, which may otherwise compromise the reliability and accuracy of the applied investigation.

Our empirical findings contribute to the understanding of the housing market in two respects. Firstly, we observe several statistically significant structural breaks or fast-moving institutional changes and their dates appear to better match unexpected market shocks rather than political events. This finding is broadly in accordance with the views of Culpepper (2005) who suggests that a sufficient condition for institutional change is a change in ideas caused by a process by which people apply triggering events, such as financial crises, to coordinate their future anticipations around the new rules of the economy. Secondly, the three TVP models suggest that the effects of fundamental variables, such as real household disposable income on housing prices have declined over previous decades. However, housing price bubbles which reflect people's biased expectations now play a more important role than fundamental variables in the short-run. Our empirical findings are generally in contrast to the mainstream economic theories which argue that fundamentals are the dominant force in driving housing prices.

In the remainder of the paper, Section 2 describes the data. Section 3 displays the Bai and Perron (1998) structural break tests. Section 4 presents the three TVP models and the diagnostics tests. Section 5 concludes the paper. 


\section{Data Description}

The data included in this study are the Department for Communities and Local Government (DCLG) House Price Index (HPI), Retail Price Index (RPI), House Rent Index (HRI) which is derived from the Retail Price Index component of rents for housing, mortgage rates of Building Societies, composite mortgage rate of Building Societies and Banks (1995Q12007Q4 only), aggregate mortgage outstanding, real aggregate household disposable income, house completions, foreign exchange reserves (foreign currency deposits and bonds held by UK monetary authorities only), net exports of good/services and net Foreign Direct Investment (FDI) inflow from the United Kingdom. All the quarterly time series data are collected from DataStream with a time span from 1968Q2 to 2007Q4, except where specifically mentioned. The DCLG HPI uses the weighted averages method. The data used in this HPI is mortgage completion data supplied by a few large lenders. The start and end dates are determined by the availability of data for the quarterly house completions. The paper sets the House Price Index (HPI), House Rent Index (HRI) and the Retail Price Index (RPI) equal to 100 at 2002Q1. Following Martin and Morrison (2008), we calculate the Foreign Portfolio Investment (FPI) by the identity: FPI Inflow $=$ Change in Foreign Exchange Reserves - Net Exports - Net FDI Inflow. Unless specifically mentioned, all the variables are in nominal terms for two reasons. Firstly, 'there is a great deal of confusion about the role of inflation expectations in the demand for housing' (Schwab 1982). Secondly, people often fail to exclude the effect of inflation on their house investments (Akerlof and Shiller 2010). Throughout this paper, lower case letters for time-dependent variables represent the natural logarithm of their capital counterparts. $\Delta_{1}$ denotes the first difference.

Figure 1 plots the House Price Index through the period from 1968Q2 to 2007Q4. Figure 1 suggests that the UK house prices dramatically boomed from 1968Q2 to 1989Q2 and 
subsequently moved into a modest recession over the period to 1995Q1, and then boomed from 1995Q2 to 2007Q4.

Figure 1 about Here

Table 1 exhibits the results of Augmented Dickey Fuller (ADF) unit root tests on the level and the first natural log difference for each variable where the appropriate number of lagged differences is identified by the Bayesian Information Criteria (BIC). Table 1 suggests all the applied variables are non-stationary in log levels but stationary after the first log difference.

Table 1 about Here

\section{The Bai and Perron (1998) Structural Break Tests for Fast-moving Institutional}

\section{Changes}

Table 2 presents two forms of the Bai and Perron (1998) structural break tests. The univariate test is applied to the changes in house prices $\Delta_{1} h p_{t}$ only, for the purpose of detecting structural breaks or fast-moving institutional changes in UK house prices. The multivariate test is applied to house price $\Delta_{1} h p_{t}$ against mortgage outstanding $\Delta_{1} m_{t}$, mortgage rate of Building Societies $\Delta_{1} r_{t}$, house completion $\Delta_{1} h_{t}$, real aggregate household disposable income $\Delta_{1} y_{t}$, foreign portfolio investment $\Delta_{1} f p i_{t}$ and general index of retail price $\Delta_{1} p_{t}$ at the first natural log difference scale. The multivariate test has the purpose of detecting fast-moving institutional changes in the UK housing market, which is related to this group of economic variables.

Table 2 about Here

From Table 2, the UDmax test and the WDmax test consistently reject the null hypotheses that there are no structural breaks. However, there are inconsistencies about the dates of the 
breaks. In the univariate tests, the $\operatorname{SupF}_{T}(1)$ test and Sequential Procedure tests fail to reject the null hypotheses that there are no structural breaks in UK house prices. The tests $\operatorname{SupF}_{T}(2)$ through $\operatorname{SupF}_{T}(5)$ are statistically significant and suggest that there are 2 to 5 structural breaks, respectively. The LWZ and BIC suggest there are two structural breaks or fast-moving institutional changes at 1987Q3 and 1996Q2. In the multivariate tests, the tests $\operatorname{SupF}_{T}(1)$ through $\operatorname{SupF}_{T}(5)$ suggest there are 5 structural breaks. The tests $\operatorname{SupF}_{T}(2 \mid 1)$ through $\operatorname{SupF}_{T}(4 \mid 3)$ suggest there are 4 statistically significant structural breaks. The Sequential Procedure test, LWZ and BIC suggest that there are 3 statistically significant structural breaks. For the sake of prudence, we identify the statistically significant structural breaks at 1973Q4, 1987Q4 and 1997Q2 by following the global information criteria BIC for multivariate tests (Bai and Perron 1998).

The first structural break 1973Q4 roughly follows the collapse of the Bretton Woods Agreement in 1971, the 1973 oil crisis, and the Secondary Banking Crisis of 1973-1975. The second structural break, 1987Q4, follows the UK Building Societies Act 1986 which deregulated Building Societies, the Lawson economic boom from 1986 to 1988, the 'Big Bang' which deregulated the financial markets in London in 1986, the general election in June 1987, and the Black Monday stock market crash on $19^{\text {th }}$ October 1987 . Finally, 1997Q2 follows the UK recession in 1992, the US savings and loan crisis in the early 1990s, the 1994 economic crisis in Mexico, the 1997 Asian financial crisis and/or the UK general election in May 1997. In terms of timing, the dates of the structural breaks appear to better match unexpected market shocks rather than political events. However, some of the political and/or economic issues would be the real drivers of the market shocks (Whelan 2010). Culpepper (2005) argues that the unexpected shocks, in particular financial crises, often drive people to coordinate their future anticipations around the new rules of the economy, and thereby lead to statistically significant structural breaks. The empirical results in Table 2 are broadly 
consistent with the views of Culpepper (2005) who suggests that political and/or legal reform is often a necessary but insufficient condition for statistically significant fast-moving institutional changes, given that people's shared beliefs can persist even after changing the formal laws.

Building on a sample from 1971Q4 to 1989Q2, Brown et al. (1997) use the Chow (1960) structural break test to find that 1983Q2 was a statistically significant structural break in the UK. Given that 1983Q2 was in the middle of the recession of the early 1980s in the UK, the findings of Brown et al. (1997) are essentially consistent with the implication of Table 2. Guirguis et al. (2005) empirically support the coefficient instability of the US housing market by using three statistical tests including, the rolling OLS, the Chow (1960) test and the RESET test. Unfortunately, Guirguis et al. (2005) fail to detect the numbers and the possible dates of the structural breaks.

The Chow (1960) test is a linear regression based on a known break point model, which is essentially a test of parameter constancy or homogeneity. In practice, one has two options: to pick an arbitrary potential break point; or to pick a break point based on some known characteristic of the time series. In the earlier case, the real break point can be missed. In the latter case, the tests can be misleading due to the candidate break points being endogenous. Moreover, people can easily obtain distinctly different results, given that the selection of candidate break points is more art than science. By contrast, the Bai and Perron (1998) test is an unknown break point test. The Bai and Perron (1998) break test can extend to more than one break point given the maximum number of possible breakpoints that are known (Hansen 2001). 


\section{The Time Varying Parameter Models for Slow-moving Institutional Changes}

\subsection{Time Varying Parameter with Principal Component Analysis (TVP-PCA)}

As a first step, the paper extracts principal components from a number of economic variables, which are related to the changes in house prices $\Delta_{1} h p_{t}$. As a second step, the paper estimates the changes in house prices $\Delta_{1} p h_{t}$ against the selected principal components, by using the TVP in the form of a state space model, which is in the spirit of Principal Component Regression.

Measurement Equation:

$\Delta_{1} h p_{t}=s v_{k, t} P C_{k, t}+c_{0}+\varepsilon_{t}$

State Equation with Random Walk Specification:

$s v_{k, t}=s v_{k, t-1}+u_{t}$

$\left(\varepsilon_{t}, u_{t}\right)^{\prime} \sim N\left(\left(\begin{array}{l}0 \\ 0\end{array}\right),\left(\begin{array}{cc}\sigma^{2} & 0 \\ 0 & Q\end{array}\right)\right)$

Throughout the paper, $s v_{k, t}$ is the time varying coefficient for the $k$-th independent variable, such as principal component $P C_{k, t}$ at time $t . c_{0}$ is the constant. $\varepsilon_{t}$ and $u_{t}$ are the temporary and permanent disturbance terms, respectively. $\varepsilon_{t}$ and $u_{t}$ are Gaussian disturbances, which are serially independent and independent of each other over the sample. Once the TVP models are specified as equations (1) through (3), the time varying coefficients $s v_{k, t}$ can be estimated by using the Kalman filter. The state space model has three unknown parameters 
$\Psi=\left(c_{0}, \sigma_{\varepsilon_{t}}^{2}, \sigma_{u_{t}}^{2}\right)^{\prime}$, which are estimated by EVIEWS 7. $\Psi$ are termed as hyperparameters and are estimated by Maximum Likelihood Estimation (MLE) using the Marquardt algorithm (Van den Bossche 2011), in this paper. The state equation is defined as a random walk process. Engle and Granger (1987) and Brown et al. (1997) suggest that 'for many data sets the simple random walk process... performs well' and believe the random walk process to be an appropriate specification when there are changes in the policy regime.

In the housing literature, one of the main challenges is the 'curse of dimensionality'. For serially correlated variables, the number of parameters of a model often increases significantly when the order of the model is increased. As a statistical factor model, the aim of a Principal Component Analysis (PCA) is to identify and extract, from a number of possibly related stationary variables, a few uncorrelated common factors, named principal components which can attribute to most of the variations in the covariance or correlation matrix of the variables. The first principal component accounts for as much of the variability in the data as possible, the second greatest variability on the second principal components, and so on (Jackson 1993; Tsay 2010; Zivot and Wang 2006).

Building on the demand and supply equations in Hendry (1984), this paper applies robust PCA (Verardi and Croux 2008) to house completion $\Delta_{1} h_{t}$, Retail Price Index (RPI) $\Delta_{1} p_{t}$, real household disposable income $\Delta_{1} y_{t}$, real income per household $\Delta_{1}(y-h)_{t}$, house price $\Delta_{1} h p_{t}$, average value of housing per unit income $\Delta_{1}(h p+h-p-y)_{t}$, mortgage total outstanding $\Delta_{1} m_{t}$, mortgage rate from Building Societies $\Delta_{1} r_{t}$, ratio of borrowed to own equity $\Delta_{1}(m-h p-h)_{t}$, real mortgage value $\Delta_{1}(m-p)_{t}$, real value of the mortgage stock $\Delta_{1}(m-p-h)_{t}$, ratio of house price to incomes $\Delta_{1}(h p-p-y)_{t}$ and foreign portfolio investment $\Delta_{1} f p i_{t}$ at the first log difference scale. Relative to the standard PCA application, Verardi and Croux (2008)'s robust PCA eliminates the outlier effects. 
By applying the correlation matrix approach, Table 3 shows the results of the robust PCA. Because of collinearity, a number of variables such as changes in house completion $\Delta_{1} h_{t}$ are removed. Therefore, the robust PCA actually applies to the real household disposable income $\Delta_{1} y_{t}$, house price $\Delta_{1} h p_{t}$, average value of housing per unit income $\Delta_{1}(h p+h-p-y)_{t}$, mortgage total outstanding $\Delta_{1} m_{t}$, mortgage rate from Building Societies $\Delta_{1} r_{t}$, real value of the mortgage stock $\Delta_{1}(m-p-h)_{t}$, and foreign portfolio investment $\Delta_{1} f p i_{t}$ at the first $\log$ difference scale.

\section{Table 3 about Here}

In Table 3, panel A shows the figures for the eigenvalues, and the (cumulative) percentage of explained variance. The eigenvalue for a given component measures the variance in all the variables, which is accounted for by that component. The difference shows the spread between one eigenvalue and the next. The proportion indicates the relative weight of each component in the total variance. The cumulative shows the amount of variance explained by the sum of the first $k$ components. Following Jackson (1993), we identify the numbers of principal components when the cumulative proportion of variance is above $90 \%$. Therefore, the first five principal components are selected which implies $k=5$ in equation (1). The paper does not present the rotated principal components, as the components rotation does not enhance the interpretation in Table 3. The rotated results are available upon request. Given the paper targets quantifying the dynamic relationships between the changes in house prices and five principal components in the UK housing market, instead of identifying the specific characteristics of each component, the paper names the principal components according to the values of the factor loadings.

In Table 3, panel B reports the factor loadings, which are the correlation coefficients between the variables (rows) and components (columns). As the first component has a factor loading 
of 0.66 on the average value of housing per unit income $\Delta_{1}(h p+h-p-y)_{t},-0.62$ on real value of the mortgage stock $\Delta_{1}(m-p-h)_{t}$, and quite low loadings on the reminder of variables it is named the house value and leverage factor. In the same way, the second principal component is named the house price appreciation factor. The third principal component is the credit availability factor. The fourth and fifth principal components are named the personal disposal income factor and the foreign capital factor, respectively. Considering the components might have substantial factor loadings on some other variables, it is somewhat problematic to assume a specific component has the same characteristics as the underlying variables. For instance, the performance of the fourth principal component might differ significantly from the real household disposable income $\Delta_{1} y_{t}$, simply because the component also has very high loadings on the mortgage rate $\Delta_{1} r_{t}(0.27)$, and these variables often have quite different characteristics.

We then estimate the changes in house price $\Delta_{1} p h$ against the five unrotated principal components by using the equations (1) and (2). Figure 2 shows the time varying coefficients $s v_{k, t}$ for the five principal components over the sample 1975Q1-2007Q4. This is because there are spikes in the diagrams which correspond to having an exact fit to the data or at most 1 degree of freedom over the sample 1968Q2-1974Q4, given the TVPs are estimated by a recursive process. Throughout the paper, the notation $s v_{k, t}$ means the time varying coefficients for the $k$-th independent variable at time $t$. The time varying coefficients indicate that a one unit change in independent variable could cause about $s v_{k, t}$ unit changes in house prices at time $t$, ceteris paribus.

Figure 2 about Here

Figure 2 suggests all the coefficients declined between 1975Q1 and 2007Q4 albeit they experienced various levels of short-run recoveries. This implies that the five principal 
components or common factors, in general, play a declining role in driving the changes in house prices over the sample 1975Q1-2007Q4. Apart from the coefficient of the fifth principal component $s v_{5, t}$, the remainder of the four TVPs remain positive over the sample. The general turning points for these time varying parameters appear in 1980-1983, 19871990 and 1996-1998, which is consistent with Table 2.

\subsection{Time Varying Parameter with Principal Component Analysis and Bubble (TVP-PCA-}

\section{Bubble)}

To control for the effects of people's biased expectations on the changes in housing prices, equation (4) incorporates the changes in housing price bubble $\Delta_{1} b_{t}$ to equation (1). Part $\mathrm{A}$ of Appendices displays the estimation of changes in bubble $\Delta_{1} b_{t}$. Basically speaking, a persistent and substantial divergence between market price and the fundamental value of an asset is evidence of a bubble. In an efficient market, where the current asset price has fully, instantaneously and correctly reflected all relevant information, there are no bubbles. Thereby, the presence of bubbles suggests some non-fundamental factors such as peoples' biased forward looking expectations, played an important role in driving UK house prices (Black et al. 2006).

Measurement Equation:

$\Delta_{1} h p_{t}=s v_{k, t} P C_{k, t}+s v_{k+1, t} \Delta_{1} b_{t}+c_{0}+\varepsilon_{t}$

The remainder of the model specification is the same as equations (2) and (3). As the number of Principal Component $k=5$, the time varying coefficient for the changes in bubble $\Delta_{1} b_{t}$ is labelled as $s v_{6}$. Figure 3 plots the changes in bubble $\Delta_{1} b_{t}$ against the changes in house price $\Delta_{1} h p_{t}$ over the period from 1996Q1 to 2007Q4. Figure 3 indicates that the changes in 
bubbles $\Delta_{1} b_{t}$ roughly follow the changes in house prices $\Delta_{1} h p_{t}$. However, house price bubbles are less volatile than house prices, given that bubble is a component of house price.

Figure 3 about Here

Figure 4 plots the time varying coefficients of the TVP-PCA-Bubble over the sample 1996Q2- 2007Q4. The start dates for the TVP-PCA-Bubble are determined by the availability of data for the changes in house price bubble $\Delta_{1} b_{t}$.

Figure 4 about Here

In Figure 4, the coefficients for the five principal components change signs over time, which is in contrast to Figure 2. However, the decline of coefficients $s v_{1}$ through $s v_{5}$ over time and the dramatic volatility between 1996 and 1998 are consistent with Figure 2. After controlling for the effect of changes in bubble $\Delta_{1} b_{t}$, the coefficients for the five principal commons are smaller than 0.2 in absolute value. The coefficient for the changes in bubble $s v_{6}$ increases from 0.05 in 1996 to 0.8 in 1998, and thereafter, it remains stable and approaches 1 by 2007Q4. Given that bubble is a component of house price, a one percent change in the bubble approximately drives a one percent change in house price, after controlling for the effect of the fundamental variables. The small value of $s v_{6}$ prior to 1998 is probably due to a lack of degrees of freedom. When compared to Figure 2, Figure 4 implies that the effects of common factors on housing prices are substantially dependent on the changes in the bubble, or people's biased expectations. It is the build-up of the bubble which is driving the changes in house prices. To investigate the robustness of the house price bubbles, the authors also estimated the monthly changes in house price bubbles over the sample January 1995 to December 2007. The findings are consistent with Figure 4. 
Brown et al. (1997) study the time varying coefficients for the nominal user cost and the expected capital gains on housing separately. However, this paper treats expected capital gains as a key driver of the nominal user cost which, in turn, is a main variable in the estimation of bubbles. Furthermore, Brown et al. (1997) formulate the expected capital gains by using the backward-looking adaptive expectations, while this paper uses the forwardlooking unbiased expectations. Brown et al. (1997) suggest that the coefficient for the expected capital gains is likely to increase when house prices boom and fall when house prices are in recession periods over the sample 1968Q2-1992Q2. Given that the sample 1996Q2-2007Q4 is a typical boom period in the UK housing market, the increase of coefficient for the changes in bubble $s v_{6}$ in Figure 4 supports Brown et al. (1997). However, whether the coefficient for the biased expectations will fall in recession periods is left for future research.

\subsection{Time Varying Parameter with Error Correction Model (TVP-ECM)}

Following Li et al. (2006), this paper applies a two-step TVP-ECM. TVP-ECM accommodates an adjustment process that prevents housing variables from moving too far away from their long-run equilibrium.

Building on Hendry (1984), the first step applies the Johansen cointegration test for house price $h p_{t}$, mortgage outstanding $m_{t}$, mortgage rate (from Building Societies) $r_{t}$, house completion $h_{t}$, real household disposable income $y_{t}$, foreign portfolio investment $f p i_{t}$ and general index of retail price $p_{t}$ at the natural $\log$ scale.

From Table 4, both the trace test and the maximum eigenvalue test indicate there are four cointegrations among the seven applied variables at 5\% significance level, meaning that there are four long-run equilibrium relationships among these variables. Thereby, speculative or 
market shocks could drive house prices away from market equilibriums in the short-run but fundamentals will eventually drive the house prices to converge to their equilibrium in the long-run.

\section{Table 4 about Here}

The second step estimates the changes in house price $\Delta_{1} h p_{t}$ against the four cointegration terms, mortgage outstanding $\Delta_{1} m_{t}$, mortgage rate $\Delta_{1} r_{t}$, house completion $\Delta_{1} h_{t}$, real household disposable income $\Delta_{1} y_{t}$, foreign portfolio investment $\Delta_{1} f p i_{t}$, and the general index of retail price $\Delta_{1} p_{t}$ at the lagged first log difference scale as equation (5).

Measurement Equation:

$$
\begin{aligned}
& \Delta_{1} h p_{t}=s v_{1} \Delta_{1} m_{t-1}+s v_{2} \Delta_{1} r_{t-1}+s v_{3} \Delta_{1} h_{t-1}+s v_{4} \Delta_{1} y_{t-1}+s v_{5} \Delta_{1} f p i_{t-1}+ \\
& s v_{6} \Delta_{1} h p_{t-1}+s v_{7} \Delta_{1} p_{t-1}+s v_{8} \text { cointeg }_{1, t-1}+s v_{9} \text { cointeg }_{2, t-1}+s v_{10} \text { cointeg }_{3, t-1}+ \\
& s v_{11} \text { cointeg }_{4, t-1}+c_{0}+\varepsilon_{t}
\end{aligned}
$$

cointeg $_{i, t}$ is the $i$-th cointegration term or error correction mechanism. The state equation and the rest of the model specifications are the same for equations (2) and (3). Like Figure 2, Figure 5 shows the time varying coefficients for the TVP-ECM over the sample 1975Q12007 4.

Figure 5 about Here

In Figure 5, the coefficient for the changes in mortgage outstanding $s v_{1}$, declines between 1975 and 1982; remains stable between 1983 and 1989; declines from 1990 to 1997, and then recovers slightly. The coefficient for changes in mortgage rate (from Building Societies) $s v_{2}$, house completion $s v_{3}$ and real household disposable income $s v_{4}$ show W-shape volatiles. The coefficients for the changes in foreign portfolio investment $s v_{5}$ and the lagged changes 
in house price $s v_{6}$ increase from 1975 to 1978 and decline between 1979 and 1980. Thereafter, $s v_{5}$ remains quite stable whereas $s v_{6}$ exhibits a slight recovery from 1989 to 1990 and then remains stable. The coefficient for changes in RPI $s v_{7}$ declines from 1.1 in 1975Q1 to 0.7 at 1996Q1, recovers to 0.9 at 1993Q1, and then experiences long-term decline with modest short-run recoveries up to 2007Q4. The coefficients for the cointegration terms, $s v_{10}$ and $s v_{11}$ are initially negative but $s v_{8}$ and $s v_{9}$ are positive with slightly higher values between 1975Q1 and 1982Q2, which implies the self-correction process could drive the housing market away from equilibrium occasionally. From 1982Q3 to 2007Q4, the coefficients $s v_{8}$ and $s v_{10}$ remain negative, $s v_{9}$ converges to $0, s v_{11}$ becomes positive; and the overall effect of these four cointegration terms becomes negative, which drives the UK housing prices to converge to their long-run equilibrium. Figure 5 suggests the turning points appear in 1980-1982, 1989-1991 and 1995-1998, which are consistent with Table 2 and Figures 2.

The general declining values of $s v_{1}, s v_{4}$ and $s v_{7}$ over the sample indicate that the changes in the mortgage amount outstanding from Building Societies, real household disposable income and RPI are playing a less important role than previously. The values of $s v_{2}, s v_{3}$ and $s v_{5}$ are less than 0.05 in absolute value, suggesting that one unit changes in each of the mortgage rate (from the Building Societies), house completion and foreign portfolio investment does not substantially drive the movement of house prices, ceteris paribus.

Table 5 exhibits the results of the hypothesis tests for statistical significance of the TVPs throughout the paper. The paper does not display the confidence intervals for the TVPs primarily because the standard errors for the TVPs are generally very small. With very few exceptions, the TVPs are statistically significant at the 5\% significance level. The statistically insignificant TVPs including the coefficient for the fourth principal component in the TVP- 
PCA-Bubble model; the coefficients for the changes in mortgage rate (from Building Societies) $s v_{2}$, the changes in housing completion $s v_{3}$, the changes in foreign portfolio investment $s v_{5}$ and the second cointegration term in the TVP-ECM model. The next two paragraphs present arguments to support these empirical findings.

\section{Table 5 about Here}

Firstly, about $80 \%$ of the total assets of Building Societies eventually transferred to the banking sector, after the enactment of the UK Building Societies Act 1986 (Shiwakoti et al. 2008). The proportion of total mortgage outstanding provided by Building Societies dramatically declined from more than $60 \%$ in the mid-1980s to $14 \%$ by 2010 (O'Connor 2010). Consequently, the mortgage outstanding and the mortgage rates from the Building Societies played a declining role in driving UK housing prices. However, the user cost framework suggests the mortgage rate still plays an important role in determining the fundamental house prices (Himmelberg et al. 2005). Secondly, the real disposable income is an average evaluation that covers the aggregate population, but in the UK housing market, the specific groups of sellers and buyers that determine house prices have income that is significantly different from the population mean. Thirdly, when people purchase a home, they make their decision based not only on available information, such as the lagged changes in retail price, but also their expectations about the future. Fourthly, the number of house completion is very small in relation to the existing housing stock (Hendry 1984); and the impact of foreign portfolio investments (Whelan 2010; Xu and Chen 2012). Fifth, the spread of 'short-termism' in the UK since the 1960s, associated with financial innovations and deregulations, has driven people to treat housing as a gambling chip, becoming increasingly impatient for a quick return on their investments (Konzelmann et al. 2010). Consequently, the house price bubbles rather than the fundamental economic factors are playing a far more important role in driving the UK housing prices in the short-run. 


\subsection{Diagnostic Tests}

To assess whether the three two-step TVP models are valid, Table 6 tests the standardised prediction errors of the three TVP models in terms of independence, homoscedasticity and normality, which are listed in a decreasing order of importance (Commandeur and Koopman 2007, p.90). As the measure of the relative quality of a statistical model, Table 6 also presents the Akaike Information Criterion (AIC) and Bayesian Information Criterion (BIC).

\section{Table 6 about Here}

In Table 6, the Ljung-Box test fails to reject the residual independence and the McLeod-Li test does not reject the residual homoscedasticity for the TVP-PCA, the TVP-PCA-Bubble and the TVP-ECM. The Jarque-Bera test significantly rejects the normality of residuals for the TVP-PCA and the TVP-ECM. Table 6 indicates that the TVP-PCA-Bubble model meets the three assumptions concerning the residuals of the analysis. The TVP-PCA and the TVPECM are somewhat problematic but still provide sensible outputs, given that the residual normality is the least important assumption (Commandeur and Koopman 2007, p.90). The TVP-PCA-Bubble reports the smallest AIC and BIC, while the TVP-ECM exhibits the largest AIC and BIC. The model fit of TVP-PCA-Bubble outperforms that of the TVP-PCA which, in turn, is superior to the TVP-ECM. Overall, the findings of the three applied TVP models are valid.

\section{Conclusion}

This paper investigates the institutional changes in the UK housing market from 1968Q2 to 2007Q4 using structural break tests and time varying parameter models. From a methodological viewpoint the approach of using both structural break tests and time varying 
parameter models is motivated by models of institutional change drawn from the political science literature.

Bai and Perron (1998) break tests are used for the fast-moving (or formal) institutional changes, and three two-step TVP models, namely, TVP-PCA, TVP-PCA-Bubble and TVPECM, for the slow-moving (or informal) institutional changes. Although TVP-ECM and TVP-PCA are popularly used in dynamic forecasting, we are not aware of previous work that uses these models to quantify slow-moving institutional changes.

Our paper contributes to our understanding of the housing market in several respects. Initially, it provides empirical evidence to show that fast-moving institutional changes, such as political reforms, do not cause statistically significant structural breaks immediately. It seems that unexpected shocks, in particular financial crises, often drive people to coordinate their future anticipations around the new rules of the economy, and thereby lead to structural breaks. The TVP models suggest that changes in policies impact the housing market through the slow-moving institutional changes in particular those relating to people's preferences, technology and expectations over time. These findings provide comprehensive empirical evidence to support Roland (2004) and Culpepper (2005). Therefore, rapid political and legal interventions may not stabilize the housing market immediately and may risk driving the housing market into further uncertainty in the long-run. In addition, we find that the linkages between house prices and fundamental variables have decayed over the past decades. However, people's biased expectations of housing prices have played a much more important role in driving the UK house prices over the period 1996Q2-2007Q4, which stands in some contrast to the mainstream literature. In conclusion, housing policies and investment strategies would be wise if they take account of the long-term institutional changes in the UK housing market. 


\section{Appendices}

\section{Part A: The Estimation of Changes in Housing Prices Bubbles}

Given that an asset price is a combination of fundamental, non-fundamental or bubble and model misspecification error ( $\mathrm{Wu} 1997)$, we can write the changes in house price as

$\Delta_{1} h p_{t}=\Delta_{1} h p_{t}^{f}+\Delta_{1} b_{t}+\varepsilon_{t}$

Where, $\Delta_{1} h p_{t}$ is the changes in house price, $\Delta_{1} h p_{t}^{f}$ is the changes in fundamental house price, and $\Delta_{1} b_{t}$ is the changes in bubble, $\varepsilon_{t}$ is error term. Because $\log _{e}\left(H P I_{t}^{f}\right)=\log _{e}\left(H P I_{t}^{f} /\right.$ $\left.H R I_{t}\right)+\log _{e}\left(H R I_{t}\right)$, we can rewrite equation (A1) as

$\Delta_{1} h p_{t}=\Delta_{1} h p_{t}^{f}+\Delta_{1} b_{t}+\varepsilon_{t}=\left(\Delta_{1} p r_{t}^{f}+\Delta_{1} h r i_{t}\right)+\Delta_{1} b_{t}+\varepsilon_{t}$

$\Delta_{1} p r_{t}^{f}$ is the changes in fundamental price-rent ratio, $\Delta_{1} h r i_{t}$ is the changes in house rent index. In equation (A2), the changes in fundamental house price-rent ratio $\Delta_{1} p r_{t}^{f}$ and the changes in bubble $\Delta_{1} b_{t}$ are not directly observable and need algebraic estimation. As a first step, the paper estimates the fundamental house price-rent ratio $p r_{t}^{f}$ by using the user cost framework. The user cost framework suggests that at the equilibrium house price $H P I_{t}^{f}$, the cost of holding a house per year $U C_{t} \times H P I_{t}^{f}$ equals the cost of renting the house $H R I_{t}$ for that period, namely,

$H R I_{t}=U C_{t} \times H P I_{t}^{f}$ 
$U C_{t}$ is the user cost of holding a house per year at the percentage level. Then, the fundamental house price-rent ratio $P R_{t}^{f}$ is the inverse of the user cost $U C_{t}$.

$P R_{t}^{f}=\frac{H P I_{t}^{f}}{H R I_{t}}=\frac{1}{U C_{t}}$

At the percentage level:

$U C_{t}=R_{t}^{m}+P T_{t}+M C_{t}+R P_{t}-M T_{t}\left(R_{t}^{m}+P T_{t}\right)-C G_{t+1}$

Where, $R_{t}^{m}$ is the foregone mortgage rate, $P T_{t}$ is the property tax rate, $M C_{t}$ is the maintenance cost, $R P_{t}$ is the risk premium for the larger uncertainty of purchasing relative to renting, $M T_{t}$ is the marginal tax rate for the house buyer. $C G_{t+1}$ is the expected capital gain over the next year. This paper estimates the expected capital gain $C G_{t+1}$ as the realized capital gain over the next year

$C G_{t+1}=\frac{H P I_{t+1}}{H P I_{t}}-1=\frac{H P I_{t+1}-H P I_{t}}{H P I_{t}}$

The rationale is that if people are rational when forming their capital gain expectations, the expectation error should be independent and normally distributed with a mean of zero on average over time. In line with the rationale used for the expected capital gain $C G_{t+1}$, Equation (A7) calculates the risk premium as the difference between the house price appreciation and the rent appreciation over the next year.

$R P_{t}=C G_{t+1}-\frac{H R I_{t+1}-H R I_{t}}{H R I_{t}}=\frac{H P I_{t+1}-H P I_{t}}{H P I_{t}}-\frac{H R I_{t+1}-H R I_{t}}{H R I_{t}}$ 
Because the paper uses quarterly data, the annual changes in rent are the changes in rent over the next four quarters. We follow the literature (Girouard et al. 2006; Himmelberg et al. 2005) in presuming that maintenance cost rate $M C_{t}=2 \%$. According to the UK Mortgage Interest Relief at Source (MIRAS) scheme, we set the UK marginal tax rate $M T_{t}=20 \%$ from 1983Q2 to $1995 \mathrm{Q} 1, M T_{t}=15 \%$ from $1995 \mathrm{Q} 2$ to $1998 \mathrm{Q} 1, M T_{t}=10 \%$ from $1998 \mathrm{Q} 2$ to 2000Q1, and $M T_{t}=0$ thereafter. Mortgage Interest Relief at Source (MIRAS) was a government scheme launched in the UK in 1969 for the purpose of encouraging house ownership; it allowed borrowers to claim tax relief at their marginal rate for interest payments on their mortgage. MIRAS was abolished in April 2000. The paper uses the composite mortgage rates from Building Societies and Banks over the sample 1995Q1-2007Q4 to proxy $R_{t}^{m}$. The start date for the estimation of user cost is chosen based on the availability of the composite mortgage rates. The end date is chosen based on the availability of the house completion data which is be used in the TVP-PCA-Bubble model. This paper sets the UK property tax rate $P T_{t}=0$ for two reasons. Firstly, property tax payment is not deductible from income tax under the UK tax system. Secondly, it is the tenant rather than the landlord that is responsible for paying the property tax in general, in the UK. As property tax is usually not included in the rent, property tax should be removed from the user cost as well. In the typical user cost literature, in particular the US literature (Finicelli 2007; Girouard et al. 2006; Himmelberg et al. 2005; Quigley and Raphael 2004), the property tax rate $P T_{t}$ is usually set as a constant throughout the full sample period, e.g., $2 \%$ or $3 \%$, which reflects the overall property tax rate on the housing market.

As a second step, the paper estimates the changes in bubble $\Delta_{1} b_{t}$ by using a state space modelling.

Measurement equation: 
$\Delta_{1} h p_{t}=c_{1} \Delta_{1} p r_{t}^{f}+c_{2} \Delta_{1} h r i_{t}+\Delta_{1} b_{t}+c_{3}$

(A8)

State equation:

$\Delta_{1} b_{t}=c_{4} \Delta_{1} b_{t-1}+c_{5}$

(A9)

$c_{3} \sim$ i.i.d. $N\left(0, \sigma_{c_{3}}^{2}\right)$

$(\mathrm{A} 10)$

$c_{5} \sim$ i.i.d. $N\left(0, \sigma_{c_{5}}^{2}\right)$

(A11)

$E\left(c_{3}, c_{5}^{\prime}\right)=0, E\left(c_{3}, b_{0}^{\prime}\right)=0$

and

$E\left(c_{5}, b_{0}^{\prime}\right)=0$

(A12)

$c_{3}$ and $c_{5}$ are the error terms. $b_{0}^{\prime}$ is the initial state vector. The five unknown parameters $\left(c_{1}, c_{2}, \sigma_{c_{3}}^{2}, c_{4}, \sigma_{c_{5}}^{2}\right)^{\prime}$ are hyperparameters and are estimated by Maximum Likelihood Estimation (MLE) with Marquardt algorithm.

There are no constants in equation (A8) and equation (A9), given that the expected return of housing will be zero when the changes in fundamental value and bubble are both zero. The rationale for using an $\mathrm{AR}(1)$ for the changes in bubble process is based on the assumption that people will naively extrapolate the most recent changes in bubble into the next period (Wu 1997). The state space model step simplifies the model building process relative to $\mathrm{Wu}$ (1997) and Black et al. (2006) while maintaining the advantages of a state space model. 
The diagnostic tests concerning the residuals of the State Space model for the estimation of changes in bubbles suggest that the residuals are independent, homoscedastic and normally distributed. Given that the assumptions for the state space model are fulfilled (Commandeur and Koopman 2007, p.90), the estimation of changes in bubbles $\Delta_{1} b_{t}$ are creditable. More detailed results for the diagnostic tests are available upon request.

\section{Part B: Tables}

Table 1 ADF Unit Root Test

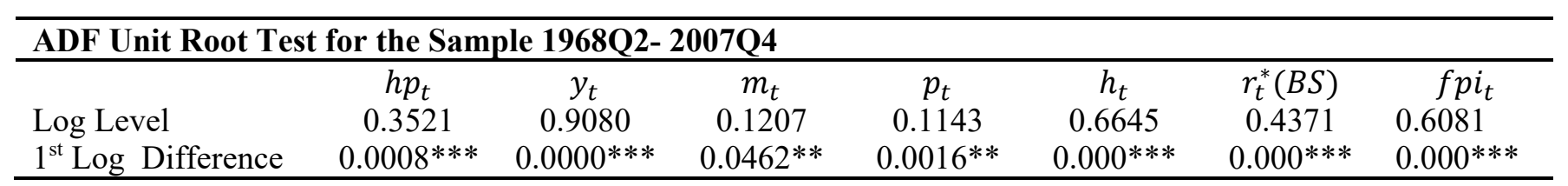

Notes: $h p_{t}$ is the house price index, $y_{t}$ represents the real household disposable income, $m_{t}$ is the mortgage outstanding, $p_{t}$ is the general index of retail price. $h_{t}$ is the physical housing stock. $r^{*}(B S)_{t}$ is the mortgage rate from Building Societies. The composite mortgage rate from Building Societies and Banks for the sample 1995Q1- 2007Q4 are stationary at first natural log difference. The figures shown in the table are $p$-values. $* * *, * *$ and $*$ denote statistical significance at the $1 \%$ and $5 \%$ significance level, respectively. The appropriate number of lagged difference for the ADF unit root test is identified by the Bayesian Information Criteria (BIC). The ADF testing procedure follows Enders (2010). 
Table 2 Bai and Perron (1998) Structural Break Tests

\begin{tabular}{|c|c|c|c|c|c|}
\hline \multicolumn{6}{|c|}{ Bai and Perron (1998) structural break test for $\Delta_{1} h p_{t}$} \\
\hline $\operatorname{SupF}_{T}(1)$ & $\operatorname{SupF}_{T}(2)$ & $\operatorname{Sup}_{T}(3)$ & $\operatorname{SupF}_{T}(4)$ & $\operatorname{SupF}_{T}(5)$ & $\operatorname{SupF}_{T}(2 \mid 1)$ \\
\hline 6.149 & $25.010^{* * *}$ & $19.309 * * *$ & $14.644 * * *$ & $12.203 * * *$ & $34.300^{* * *}$ \\
\hline $\operatorname{SupF}_{T}(3 \mid 2)$ & $\operatorname{SupF}_{T}(4 \mid 3)$ & $\operatorname{SupF}_{T}(5 \mid 4)$ & UDmax & WDmax & / \\
\hline 1.887 & 3.139 & 2.019 & $25.010 * * *$ & $32.064 * * *$ & / \\
\hline \multicolumn{3}{|c|}{ Number of breaks selected } & \multicolumn{3}{|c|}{ Identified break dates } \\
\hline Sequential Procedure & LWZ & BIC & l & $77^{\text {th }}$ Observation & $112^{\text {th }}$ Observation \\
\hline 0 & 2 & 2 & 1 & 1987Q3 & 1996Q2 \\
\hline \multicolumn{6}{|c|}{ Bai and Perron (1998) structural break test for $\Delta_{1} h p_{t}$ against $\Delta_{1} m_{t}, \Delta_{1} r_{t}, \Delta_{1} h_{t}, \Delta_{1} y_{t}, \Delta_{1} f p i_{t}$ and $\Delta_{1} p_{t}$} \\
\hline $\operatorname{SupF}_{T}(1)$ & $\operatorname{SupF}_{T}(2)$ & $\operatorname{SupF}_{T}(3)$ & $\operatorname{SupF}_{T}(4)$ & $\operatorname{SupF}_{T}(5)$ & $\operatorname{Sup}_{T}(2 \mid 1)$ \\
\hline $1202.66^{* * *}$ & $547.291 * * *$ & $192781.92 * * *$ & $6084796.474 * * *$ & $5267225.103 * * *$ & $62.386^{* * *}$ \\
\hline $\operatorname{SupF}_{T}(3 \mid 2)$ & $\operatorname{SupF}_{T}(4 \mid 3)$ & $\operatorname{SupF}_{T}(5 \mid 4)$ & UDmax & WDmax & 1 \\
\hline $58.586^{* * *}$ & $62.386 * * *$ & 9.641 & $6084796.474 * * *$ & $8061287.479 * * *$ & / \\
\hline \multicolumn{3}{|c|}{ Number of breaks selected } & \multicolumn{3}{|c|}{ Identified break dates } \\
\hline Sequential Procedure & LWZ & $\mathrm{BIC}$ & $22^{\text {th }}$ Observation & $78^{\text {th }}$ Observation & $116^{\text {th }}$ Observation \\
\hline 3 & 3 & 3 & 1973Q4 & 1987Q4 & 1997Q2 \\
\hline
\end{tabular}

Notes: $\Delta_{1} h p_{t}$ is house price, $\Delta_{1} m_{t}$ means mortgage outstanding, $\Delta_{1} r_{t}$ means mortgage rate of Building Societies, $\Delta_{1} h_{t}$ means house completion, $\Delta_{1} y_{t}$ means real aggregate household disposable income, $\Delta_{1} f p i_{t}$ means foreign portfolio investment, and $\Delta_{1} p_{t}$ means the general index of retail price at the first natural log difference scale. In the Bai and Perron (1998) tests, the paper sets the maximum number of break points $m=5$, minimum length of distance 
equals 23, trimming equals 0.10 . The sample size ranges from 1968Q2 to 2007Q4. *** denotes statistical significance at the $1 \%$ significance level. The null hypothesis for $\operatorname{SupF}_{T}(m)$ test is that there are $m$ statistical structural breaks, where, $1 \leq m \leq 5$. The null hypothesis for $\operatorname{SupF}_{T}(m+1 \mid m)$ test is that there are $m+1$ statistically significant structural breaks conditional on $m$ structural breaks. The null hypothesis for the UDmax test and the $W D \max$ test is that there is no structural break. BIC is Bayesian Information Criteria and LWZ is a modified Schwarz's Criteria. Sequential Procedure, LWZ and BIC test for the number of breaks selected, respectively.

Table 3 Results of Robust PCA

Panel A:

\begin{tabular}{ccccc}
\hline Component & Eigenvalue & Difference & Proportion & Cumulative \\
\hline Comp1 & 2.1789 & 0.6613 & 0.3113 & 0.3113 \\
Comp2 & 1.5176 & 0.3603 & 0.2168 & 0.5281 \\
Comp3 & 1.1573 & 0.1220 & 0.1653 & 0.6934 \\
Comp4 & 1.0353 & 0.2745 & 0.1479 & 0.8413 \\
Comp5 & 0.7608 & 0.4158 & 0.1087 & 0.9500 \\
Comp6 & 0.3449 & 0.3398 & 0.0493 & 0.9993 \\
Comp7 & 0.0052 & $/$ & 0.0007 & 1.0000 \\
\hline
\end{tabular}

Panel B: Principal components (Eigenvectors)

\begin{tabular}{cccccccc}
\hline Variable & Comp1 & Comp2 & Comp3 & Comp4 & Comp5 & Comp6 & Comp7 \\
\hline$\Delta_{\mathbf{1}} \boldsymbol{y}_{\boldsymbol{t}}$ & -0.0426 & -0.0290 & 0.1497 & 0.9153 & 0.3650 & 0.0201 & 0.0595 \\
$\Delta_{\mathbf{1}} \boldsymbol{p h}$ & 0.2514 & $\mathbf{0 . 6 5 7 0}$ & 0.1982 & 0.0722 & -0.1195 & -0.6492 & -0.1578 \\
$\Delta_{\mathbf{1}}(\boldsymbol{p h}+\boldsymbol{h}-\boldsymbol{p}-\boldsymbol{y})_{\boldsymbol{t}}$ & $\mathbf{0 . 6 6 1 1}$ & -0.0717 & -0.0245 & -0.0891 & 0.1907 & -0.0428 & 0.7149 \\
$\Delta_{\mathbf{1}} \boldsymbol{m}_{\boldsymbol{t}}$ & 0.2047 & 0.0246 & $\mathbf{0 . 8 0 3 0}$ & 0.0155 & -0.3600 & 0.4260 & -0.0359 \\
$\Delta_{\mathbf{1}} \boldsymbol{r}_{\boldsymbol{t}}$ & 0.1948 & 0.4566 & $-\mathbf{0 . 5 1 5 7}$ & 0.2664 & -0.4281 & 0.4826 & 0.0243 \\
$\Delta_{\mathbf{1}}(\boldsymbol{m}-\boldsymbol{p}-\boldsymbol{h})_{\boldsymbol{t}}$ & $-\mathbf{0 . 6 2 6 3}$ & 0.1962 & 0.1158 & 0.0318 & -0.2885 & -0.1166 & 0.6768 \\
$\Delta_{\mathbf{1}} \boldsymbol{f p i}_{\boldsymbol{t}}$ & -0.1606 & $\mathbf{0 . 5 6 1 1}$ & 0.1164 & -0.2772 & $\mathbf{0 . 6 4 8 1}$ & 0.3851 & 0.0244 \\
\hline
\end{tabular}


Notes: Panel A shows the figures for the eigenvalues, and the (cumulative) percentage of explained variance. The difference shows the spread between one eigenvalue and the next. The proportion indicates the relative weight of each component in the total variance. The cumulative shows the amount of variance explained by the sum of the first $k$ components. Panel B reports the factor loadings which are the correlation coefficients between the variables (rows) and components (columns). The robust PCA (Verardi and Croux 2008) applies to real household disposable income $\Delta_{1} y_{t}$, house price $\Delta_{1} h p_{t}$, average value of housing per unit income $\Delta_{1}(h p+h-p-y)_{t}$, mortgage total outstanding $\Delta_{1} m_{t}$, mortgage rate from Building Societies $\Delta_{1} r_{t}$, real value of the mortgage stock $\Delta_{1}(m-p-h)_{t}$, and foreign portfolio investment $\Delta_{1} f p i_{t}$ at the first natural log difference scale.

Table 4 Johansen Cointegration Test

\begin{tabular}{cccc}
\hline \multicolumn{4}{l}{ Unrestricted Cointegration Rank Test (Trace) } \\
\hline No. of Cointegration(s) & Eigenvalue & Trace Statistic & p-value \\
None & 0.4554 & 266.7334 & $0.0000^{* * *}$ \\
At most 1 & 0.3755 & 171.3211 & $0.0001^{* * *}$ \\
At most 2 & 0.2505 & 97.4002 & $0.0001^{* * *}$ \\
At most 3 & 0.1789 & 52.1197 & $0.0188^{* *}$ \\
Unrestricted Cointegration & Rank Test (Maximum Eigenvalue) & \\
No. of Cointegration(s) & Eigenvalue & Max-Eigen Statistic & p-value \\
None & 0.4554 & 95.4122 & $0.0000^{* * *}$ \\
At most 1 & 0.3755 & 73.9209 & $0.0000^{* * *}$ \\
At most 2 & 0.2505 & 45.2806 & $0.0015^{* * *}$ \\
At most 3 & 0.1789 & 30.9458 & $0.0178^{* *}$ \\
\hline
\end{tabular}

Notes: Johansen cointegration test for house price $h p_{t}$, mortgage outstanding $m_{t}$, mortgage rate $r_{t}$, house completion $h_{t}$, real household disposable income $y_{t}$, foreign portfolio investment $f p i_{t}$ and general index of retail price $p_{t}$. *** and ** denote for statistical significance at the $1 \%$ and $5 \%$ significance level, respectively. The Johansen test includes a drift but no linear deterministic in the VECM for the purpose of enhancing temporal stability (Ahking 2002; Barkoulas and Baum 1997). The optimal lag length for the Johansen test is determined by the BIC for the VAR. The null hypothesis is no cointegration. 
Table 5 Statistical Significance for the Time Varying Parameters

\begin{tabular}{|c|c|c|c|c|}
\hline & Final State & Root MSE & Z-Statistic & p-value \\
\hline \multicolumn{5}{|l|}{ TVP-PCA: } \\
\hline \multirow{2}{*}{\multicolumn{4}{|c|}{$\begin{array}{l}\Delta_{1} h p_{t}=s v_{k, t} P C_{k, t}+c_{0}+\varepsilon_{t} \\
s v_{k, t}=s v_{k, t-1}+u_{t}\end{array}$}} & Equation (1) \\
\hline & & & & Equation (2) \\
\hline$s v_{1, t}$ & 0.1478 & 0.0181 & 8.1710 & 0.0000 \\
\hline$s v_{2, t}$ & 0.2370 & 0.0208 & 11.3954 & 0.0000 \\
\hline$s v_{3, t}$ & 0.5022 & 0.0367 & 13.6859 & 0.0000 \\
\hline$s v_{4, t}$ & 0.3198 & 0.1031 & 3.1028 & 0.0019 \\
\hline$s v_{5, t}$ & -0.1190 & 0.0495 & -2.4036 & 0.0162 \\
\hline \multicolumn{5}{|c|}{ TVP-PCA-Bubble: } \\
\hline \multicolumn{4}{|c|}{$\Delta_{1} h p_{t}=s v_{k, t} P C_{k, t}+s v_{k+1, t} \Delta_{1} b_{t}+c_{0}+\varepsilon_{t}$} & Equation (4) \\
\hline \multicolumn{4}{|c|}{$s v_{k, t}=s v_{k, t-1}+u_{t}$} & Equation (2) \\
\hline$s v_{1, t}$ & -0.0684 & 0.0145 & -4.7319 & 0.0000 \\
\hline$s v_{2, t}$ & -0.0417 & 0.0213 & -1.9634 & 0.0496 \\
\hline$s v_{3, t}$ & -0.1719 & 0.0407 & -4.2273 & 0.0000 \\
\hline$s v_{4, t}$ & 0.0495 & 0.0827 & 0.5985 & 0.5495 \\
\hline$s v_{5, t}$ & 0.0749 & 0.0389 & 1.9244 & 0.0543 \\
\hline$s v_{6, t}$ & 0.9691 & 0.0538 & 18.0108 & 0.0000 \\
\hline $\begin{array}{l}\text { TVP-ECM: } \\
\boldsymbol{\Delta}_{\mathbf{1}} \boldsymbol{h} \boldsymbol{p}_{t}=\boldsymbol{s v}\end{array}$ & $-1+s v_{2, t} \Delta_{1}$ & $v_{3, t} \Delta_{1} h_{t-1}$ & $y_{t-1}+s v_{5}$ & $f p i_{t-1}+$ \\
\hline
\end{tabular}




\begin{tabular}{|c|c|c|c|c|}
\hline \multicolumn{5}{|c|}{$\begin{array}{l}s v_{6, t} \Delta_{1} p h_{t-1}+s v_{7, t} \Delta_{1} p_{t-1}+s v_{8, t} \operatorname{cointeg}_{1, t-1}+s v_{9, t} \operatorname{cointeg}_{2, t-1}+s v_{10, t} \text { cointeg }_{3, t-1}+ \\
s v_{11, t} \text { cointeg }_{4, t-1}+c_{0}+\varepsilon_{t}\end{array}$} \\
\hline \multirow{2}{*}{\multicolumn{4}{|c|}{$s v_{k, t}=s v_{k, t-1}+u_{t}$}} & \multirow{2}{*}{$\begin{array}{c}\text { Equation (5) } \\
\text { Equation (2) }\end{array}$} \\
\hline & & & & \\
\hline$s v_{1, t}$ & 0.6195 & 0.1176 & 5.2689 & 0.0000 \\
\hline$s v_{2, t}$ & -0.0194 & 0.0198 & -0.9816 & 0.3263 \\
\hline$s v_{3, t}$ & -0.0215 & 0.0191 & -1.1256 & 0.2604 \\
\hline$s v_{4, t}$ & 0.3945 & 0.1135 & 3.4763 & 0.0005 \\
\hline$s v_{5, t}$ & -0.0011 & 0.0021 & -0.5030 & 0.6149 \\
\hline$s v_{6, t}$ & 0.3598 & 0.0784 & 4.5887 & 0.0000 \\
\hline$s v_{7, t}$ & 0.8531 & 0.1535 & 5.5579 & 0.0000 \\
\hline$s v_{8, t}$ & -0.0289 & 0.0114 & -2.5282 & 0.0115 \\
\hline$s v_{9, t}$ & 0.0007 & 0.0145 & 0.0451 & 0.9640 \\
\hline$s v_{10, t}$ & -0.0327 & 0.0104 & -3.1430 & 0.0017 \\
\hline$s v_{11, t}$ & 0.0664 & 0.0225 & 2.9507 & 0.0032 \\
\hline
\end{tabular}

Notes: $\Delta_{\mathbf{1}} \boldsymbol{h} \boldsymbol{p}_{\boldsymbol{t}}$ is the changes in house price. $\boldsymbol{s} \boldsymbol{v}_{\boldsymbol{k}, \boldsymbol{t}}$ is the time varying coefficient for the $\boldsymbol{k}$-th independent variable, at time $\boldsymbol{t} . \boldsymbol{P} \boldsymbol{C}_{\boldsymbol{k}, \boldsymbol{t}}$ are principal components generated from Table $3 . \boldsymbol{c}_{\mathbf{0}}$ is the constant. $\boldsymbol{\varepsilon}_{\boldsymbol{t}}$ and $\boldsymbol{u}_{\boldsymbol{t}}$ are the temporary and permanent disturbance terms, respectively. cointe $_{\boldsymbol{i}, \boldsymbol{t}}$ is the $\boldsymbol{i}$-th cointegration term or error correction mechanism generated from Table 4. Root MSE stands for Root Mean Square Error.

Table 6 Diagnostic Tests for the TVP Models

\begin{tabular}{lcccccc}
\hline & $\begin{array}{c}\text { Independence } \\
\text { (L-B Test) }\end{array}$ & $\begin{array}{c}\text { Homoscedasticity } \\
\text { (McLeod-Li Test) }\end{array}$ & $\begin{array}{c}\text { Normality } \\
\text { (J-B Test) }\end{array}$ & AIC & BIC & Remark \\
\hline TVP-PCA & 17.492 & No ARCH effect & $138745^{* * *}$ & -4.04 & -3.996 & Alright. \\
TVP-PCA-Bubble & 20.189 & No ARCH effect & 2.198 & -4.28 & -4.205 & Good Model. \\
TVP-ECM & 23.246 & No ARCH effect & $627.96^{* * *}$ & -3.45 & -3.415 & Alright. \\
\hline
\end{tabular}

Notes: The null hypothesis for the Ljung-Box (L-B) test is that the residuals are independent at $\mathrm{Q}(24)$. The null hypothesis for the Jarque-Bera (J-B) test is that the residuals are a normally distributed. $* * *$ represents statistical significance at the $1 \%$ significance level. The null hypothesis of the McLeod_Li test is the independence of returns and if it is rejected, it indicates the presence of $\mathrm{ARCH} / \mathrm{GARCH}$ nonlinear effects in the data. The residuals should satisfy independence, homoscedasticity and normality in decreasing order of importance. The diagnostic tests are applied to the standardized prediction errors (Commandeur and Koopman 2007, p.90). 


\section{Part C: Figures}

Figure 1 The UK House Price Index over the Period from1968Q2 to 2007Q4

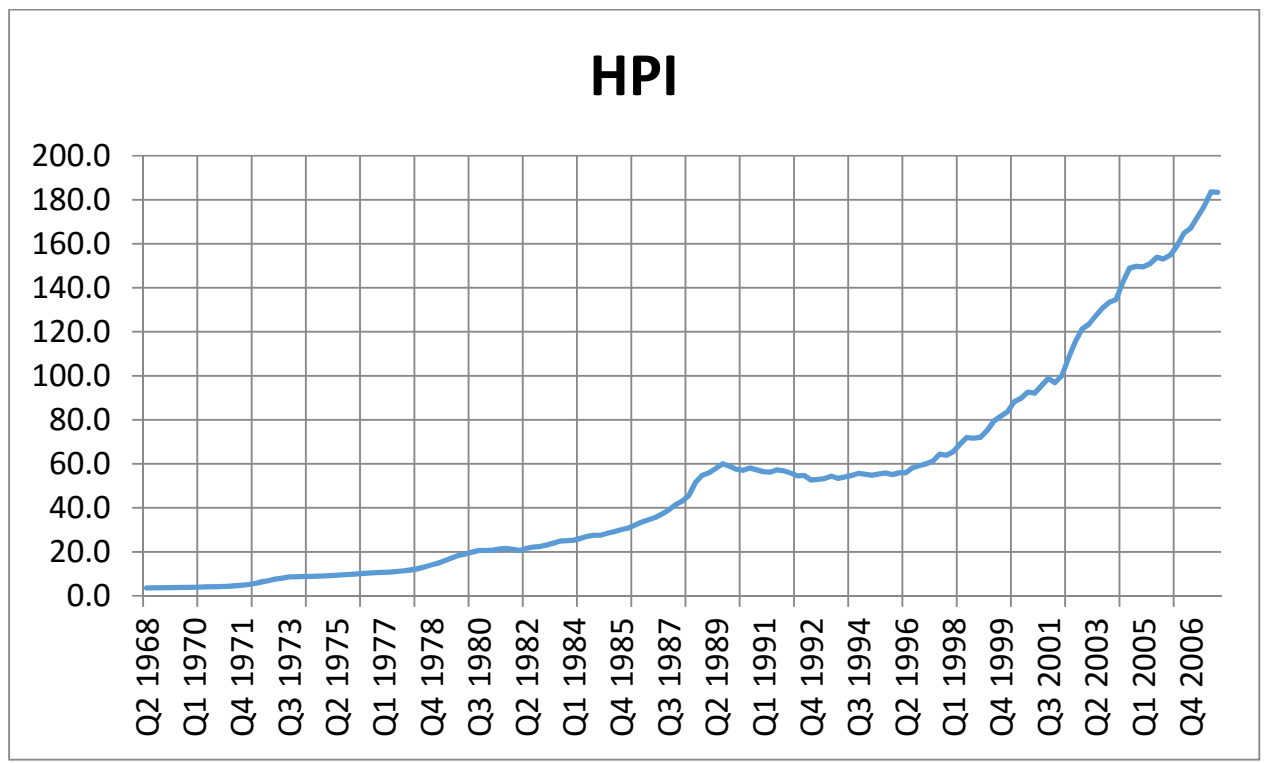

Notes: The HPI stands for the Department of Communities and Local Government (DCLG) House Price Index (HPI). The paper sets HPI equals to 100 at 2002Q1. 
Figure 2 TVP-PCA (1975Q1-2007Q4)

SV1

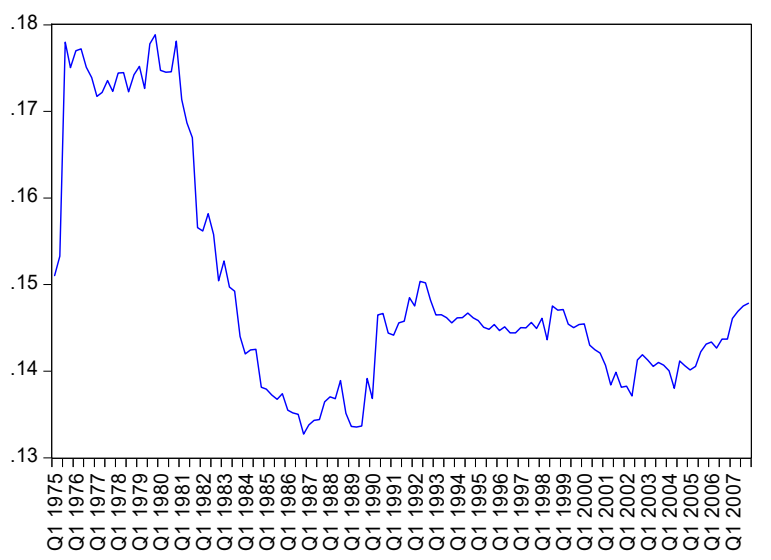

SV2

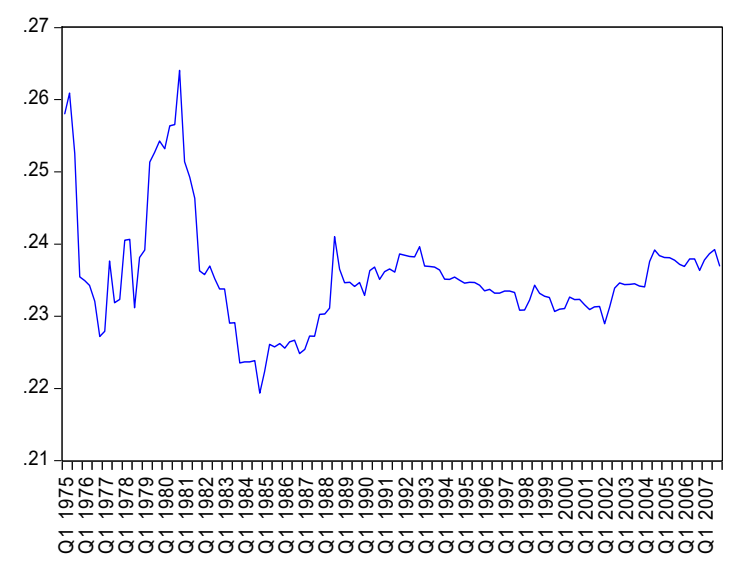




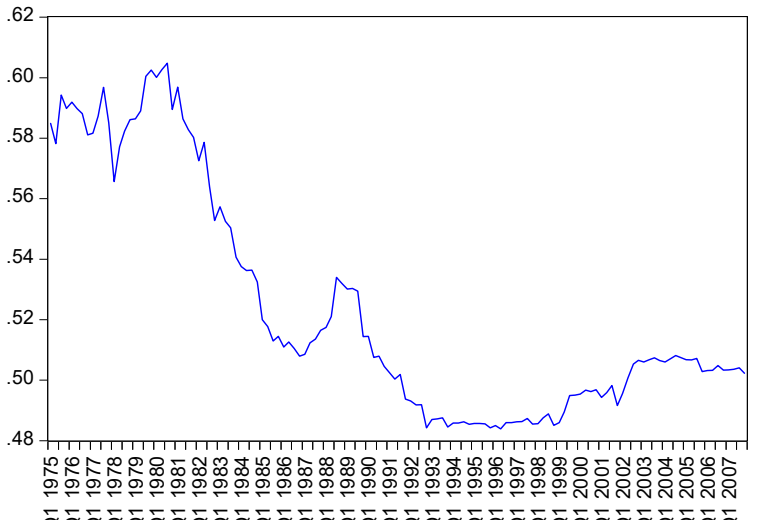

SV5

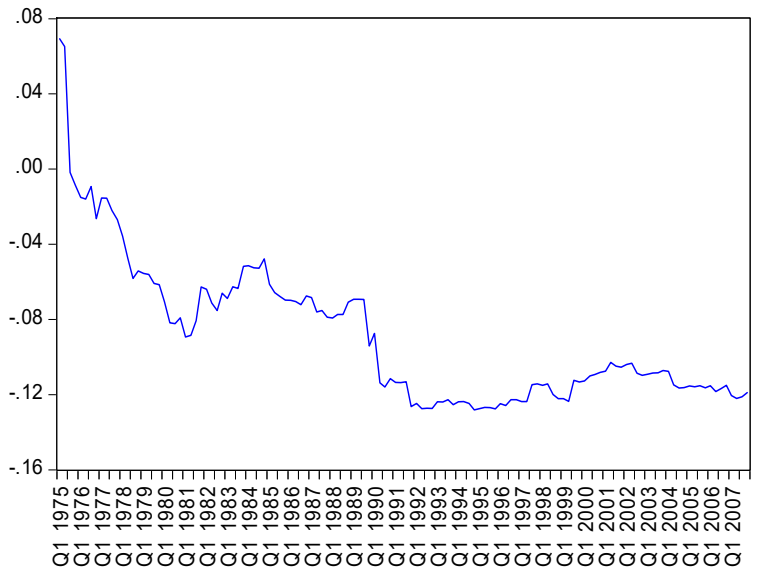

SV4

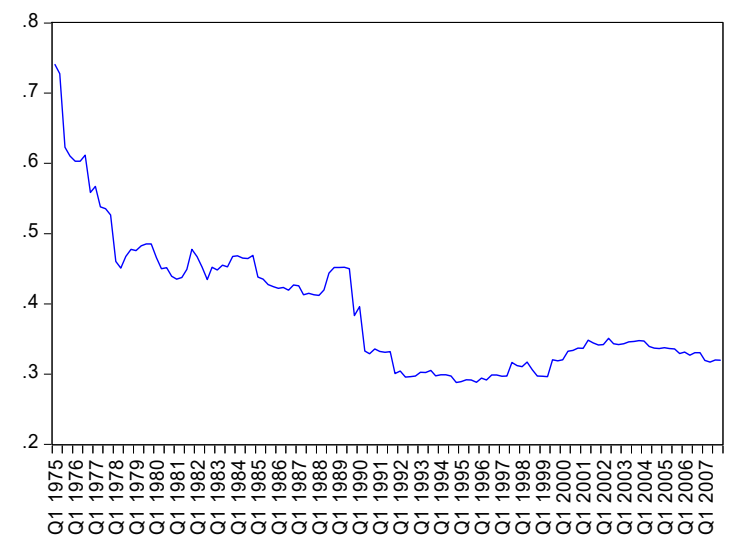

Notes: $s v_{k, t}$ is the time varying parameter for the $k$-th principal component $P C_{k, t}$ at time $t$ for equation (1), $\Delta_{1} h p_{t}=s v_{k, t} P C_{k, t}+c_{0}+\varepsilon_{t}$. Where, $s v_{k, t}=s v_{k, t-1}+u_{t} . \Delta_{1} h p_{t}$ is the changes in house price. $c_{0}$ is the constant. $\varepsilon_{t}$ and $u_{t}$ are the disturbance terms. According to Table 2, the paper sets $k=5$.

Figure 3 Changes in House Price Bubbles against the Changes in House Prices 


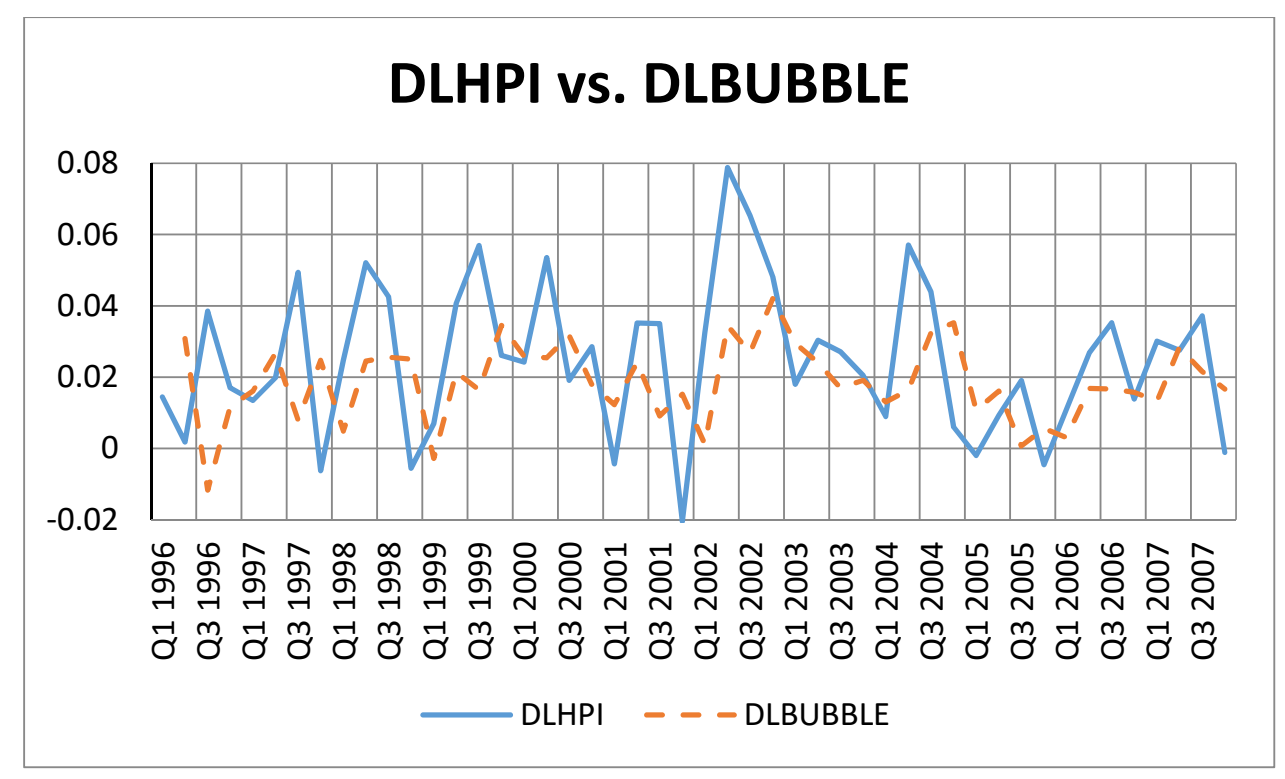

Notes: DLHPI stands for the changes in house prices $\Delta_{1} h p_{t}$, DLBUBBLE stands for the changes in house price bubbles $\Delta_{1} b_{t}$. The estimation of changes in house price bubbles $\Delta_{1} b_{t}$ can be seen from Appendences Part A.

Figure 4 TVP-PCA-Bubble (1996Q2-2007Q4) 
SV1

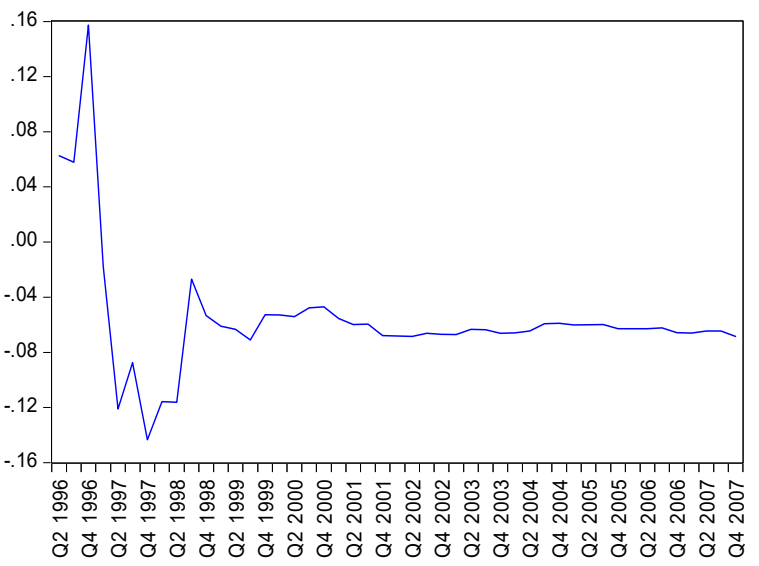

SV3

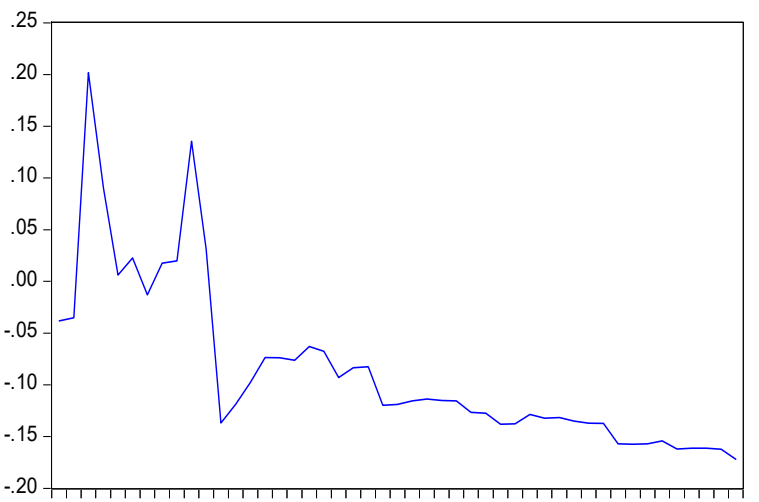

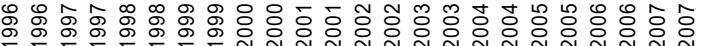

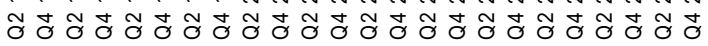

SV5

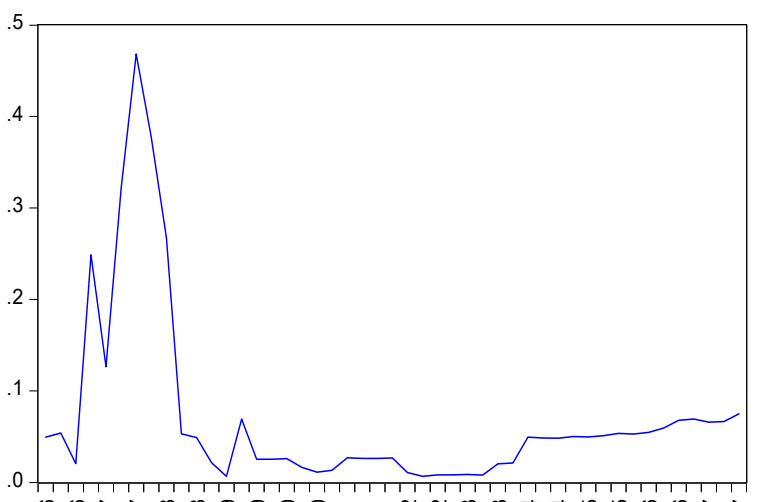

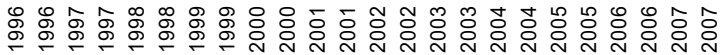

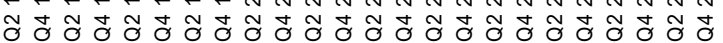

SV2

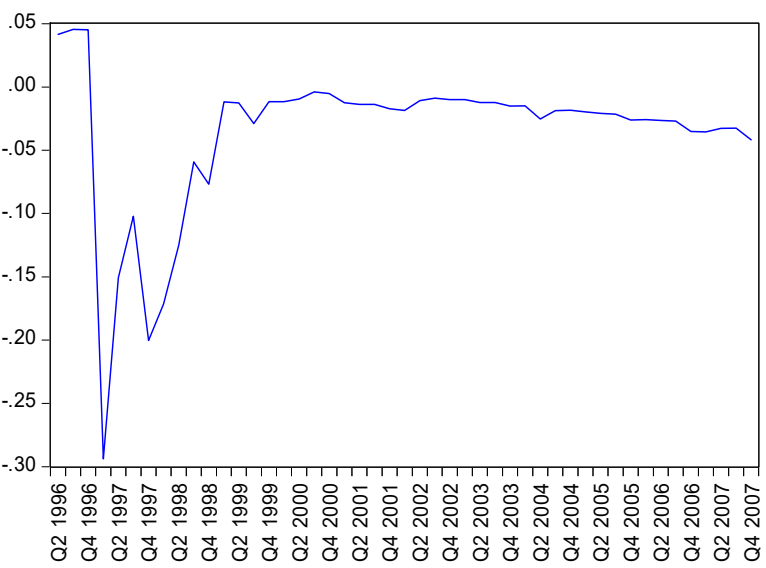

SV4

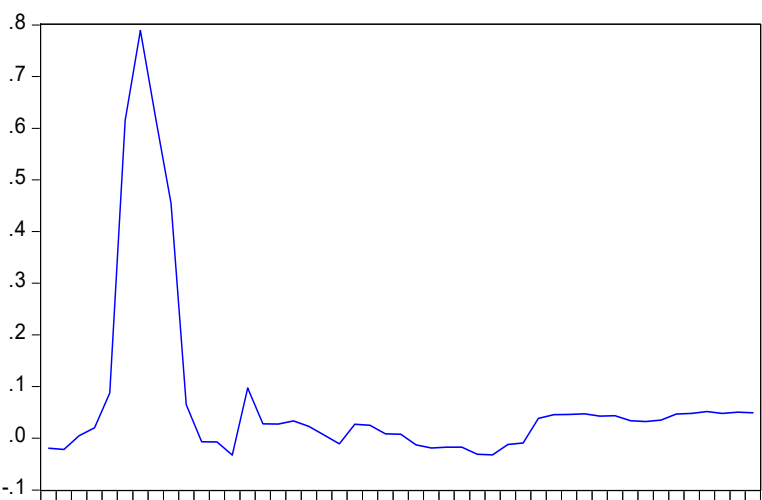

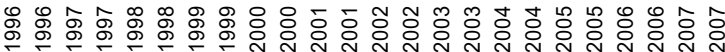

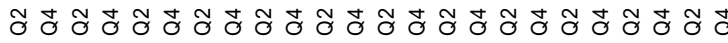

SV6

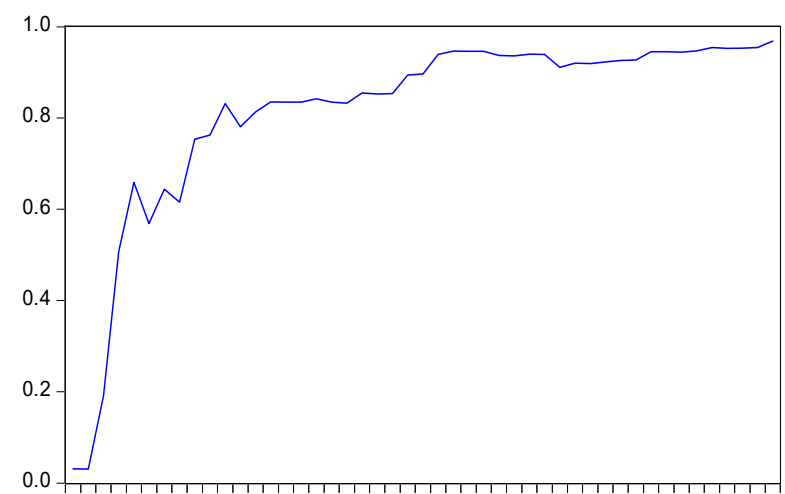

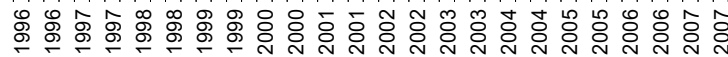

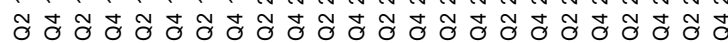

Notes: $s v_{k, t}$ is the time varying parameter (TVP) for the $k$-th independent variable at time $t$ for equation (4), $\Delta_{1} h p_{t}=s_{k, t} P C_{k, t}+s v_{k+1, t} \Delta_{1} b_{t}+c_{0}+\varepsilon_{t}$. Where, $s v_{k, t}=s v_{k, t-1}+u_{t}$. $\Delta_{1} h p_{t}$ is the changes in house price. $P C_{k, t}$ is the $k$-th principal component. $\Delta_{1} b_{t}$ is the changes in housing price bubbles. $c_{0}$ is the constant. $\varepsilon_{t}$ and $u_{t}$ are the disturbance terms. Given $k=5, s v_{6}$ is the TVP for $\Delta_{1} b_{t}$. The start and end dates are determined by the availability of data for the quarterly changes in house price bubble $\Delta_{1} b_{t}$. 
SV1
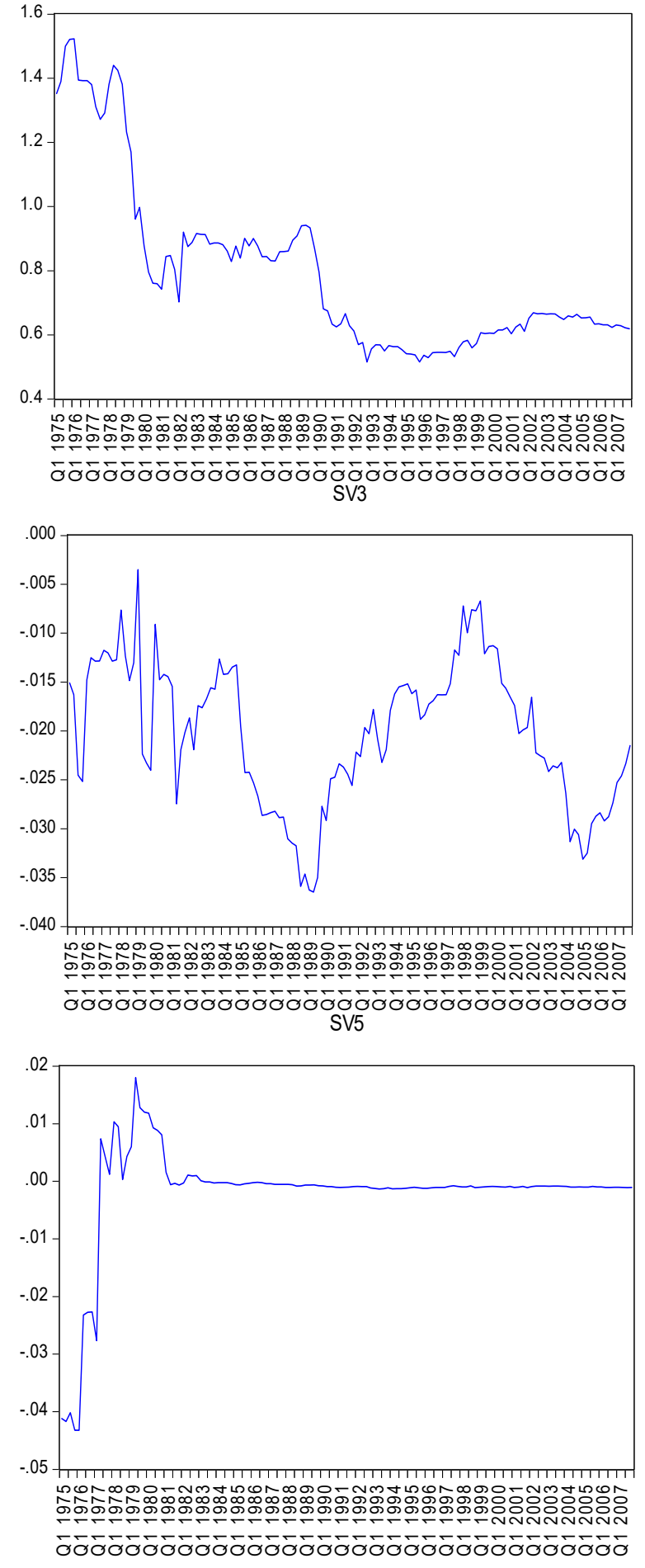

SV2
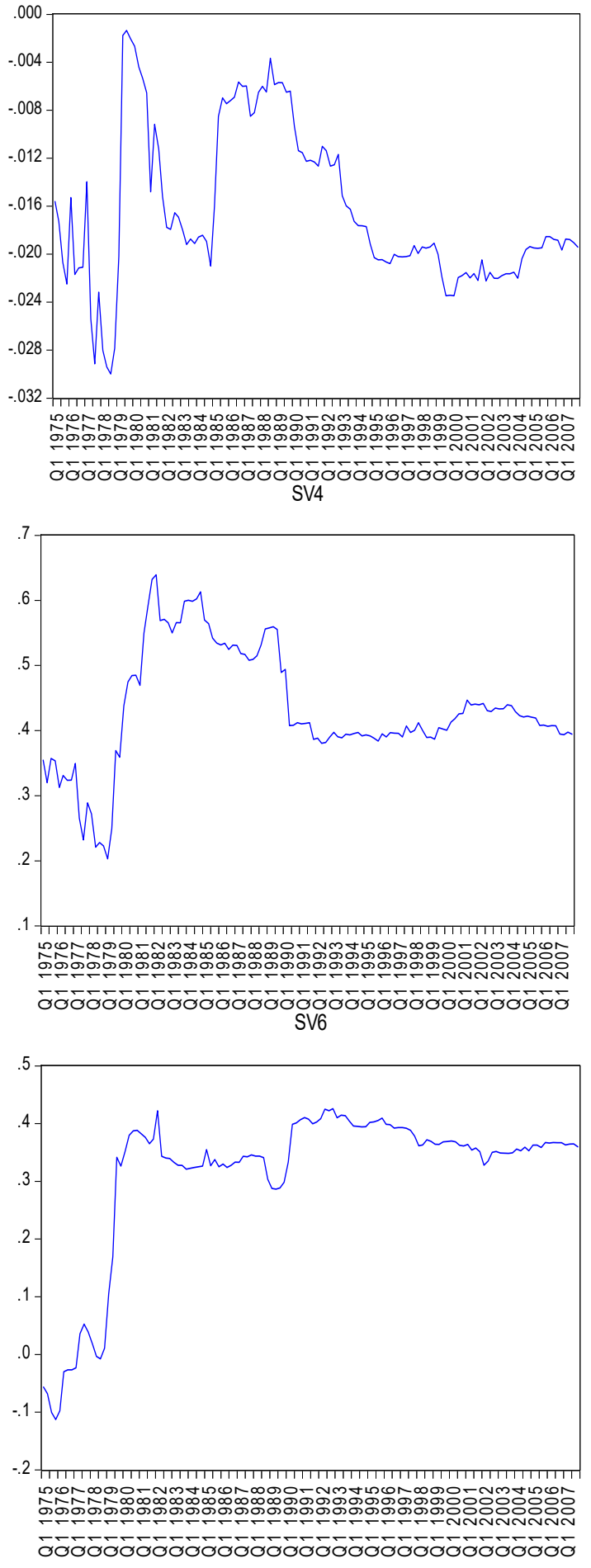

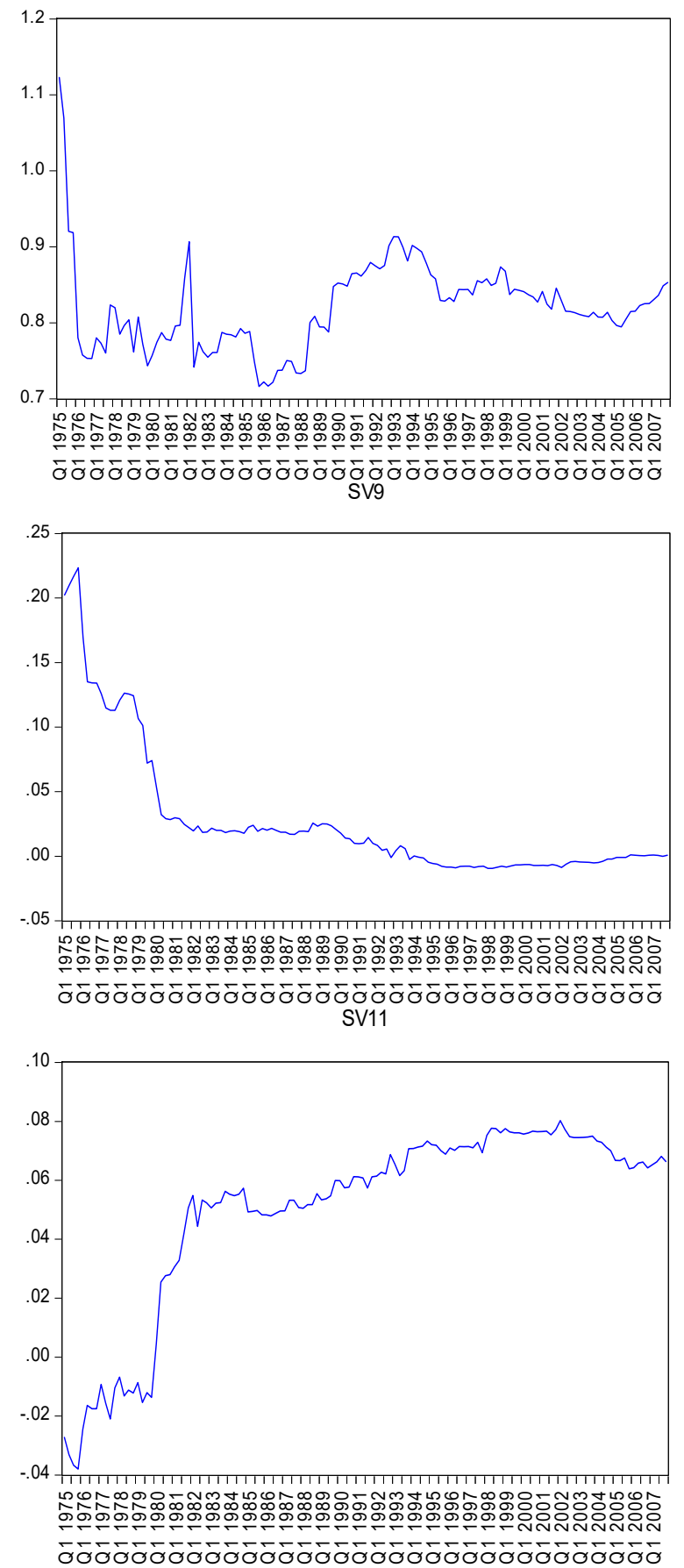

SV8
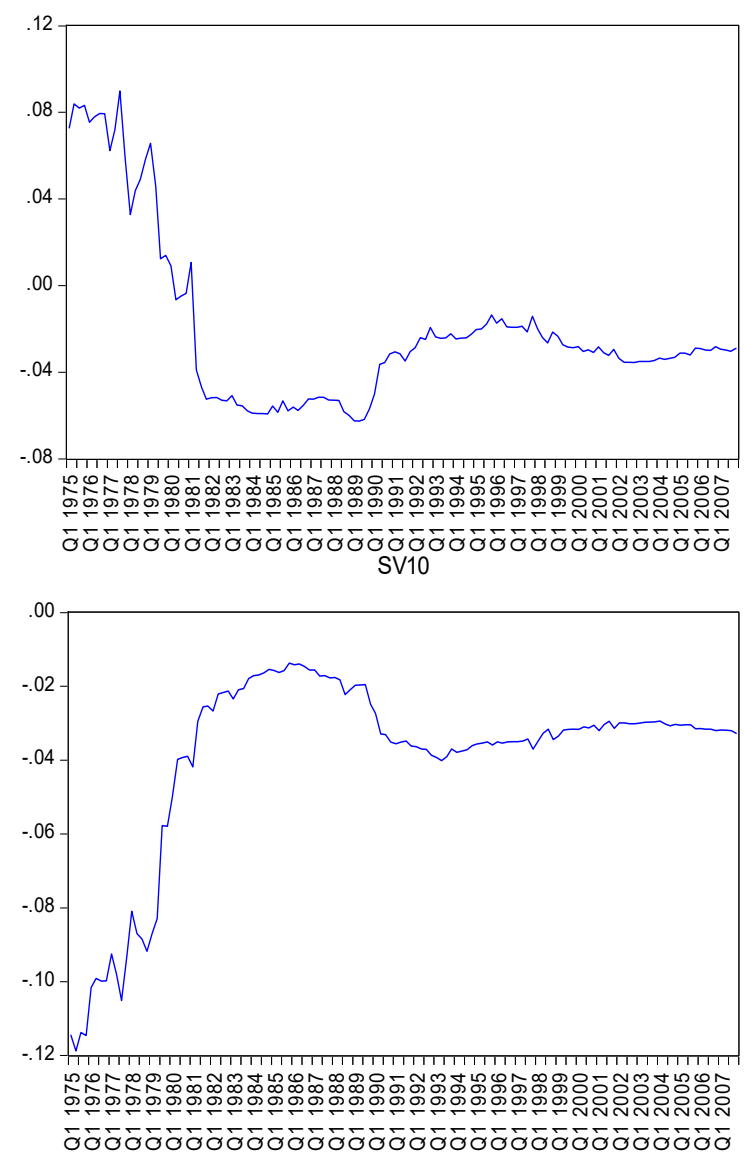

Notes: $s v_{k, t}$ is the time varying coefficient for the $k$-th independent variable at time $t$ for equation (5), $\Delta_{1} h p_{t}=s v_{1} \Delta_{1} m_{t-1}+s v_{2} \Delta_{1} r_{t-1}+s v_{3} \Delta_{1} h_{t-1}+s v_{4} \Delta_{1} y_{t-1}+s v_{5} \Delta_{1} f p i_{t-1}+$ $s v_{6} \Delta_{1} h p_{t-1}+s v_{7} \Delta_{1} p_{t-1}+s v_{8}$ cointe $_{1, t-1}+s v_{9}$ cointeg $_{2, t-1}+s v_{10}$ cointeg $_{3, t-1}+$ $s v_{11}$ cointeg $_{4, t-1}+c_{0}+\varepsilon_{t}$. Where, $s v_{k, t}=s v_{k, t-1}+u_{t}$. Equation (5) runs the changes in house price $\Delta_{1} h p_{t}$ against the mortgage outstanding $\Delta_{1} m_{t}$, mortgage rate $\Delta_{1} r_{t}$, house completion $\Delta_{1} h_{t}$, real household disposable income $\Delta_{1} y_{t}$, foreign portfolio investment $\Delta_{1} f p i_{t}$, general index of retail price $\Delta_{1} p_{t}$ at the first natural log difference scale. $c_{0}$ is the constant. $\varepsilon_{t}$ and $u_{t}$ are the disturbance terms. cointe $g_{i, t}$ is the $i$-th cointegration term or error correction mechanism generated from Table 3 . 


\section{References}

Ahking FW (2002) Model mis-specification and Johansen's co-integration analysis: an application to the US money demand. Journal of Macroeconomics 24:51-66 doi:http://dx.doi.org/10.1016/S0164-0704(02)00017-4

Akerlof GA, Shiller RJ (2010) Animal Spirits: How Human Psychology Drives the Economy, and Why It Matters for Global Capitalism (New in Paper). Princeton University Press, New Jersey

Baddeley M (2005) Housing Bubbles, Herds and Frenzies: Evidence from British Housing Markets. University of Cambridge, Cambridge

Bai J, Perron P (1998) Estimating and Testing Linear Models with Multiple Structural Changes. Econometrica 66:47-78 doi:10.2307/2998540

Barkoulas J, Baum CF (1997) A re-examination of the fragility of evidence from cointegration-based tests of foreign exchange market efficiency. Applied Financial Economics 7:635-643 doi:10.1080/758533855

Black A, Fraser P, Hoesli M (2006) House prices, fundamentals and bubbles. Journal of Business Finance and Accounting 33:1535-1555 doi:10.1111/j.14685957.2006.00638.x

Brown JP, Song H, McGillivray A (1997) Forecasting UK house prices: A time varying coefficient approach. Economic Modelling 14:529-548 doi:http://dx.doi.org/10.1016/S0264-9993(97)00006-0 
Chow GC (1960) Tests of equality between sets of coefficients in two linear regressions. Econometrica 28:591-605 doi:10.2307/1910133

Commandeur JJF, Koopman SJ (2007) An Introduction to State Space Time Series Analysis. Oxford University Press, Oxford

Culpepper PD (2005) Institutional change in contemporary capitalism: coordinated financial systems since 1990. World Politics 57:173-199 doi:10.1353/wp.2005.0016

Enders W (2010) Applied Econometric Time-Series. 3 edn. John Wiley and Sons, New York

Engle RF, Granger CWJ (1987) Co-Integration and error correction: Representation, estimation, and testing. Econometrica 55:251-276 doi:10.2307/1913236

Engle RF, Watson M (1987) The Kalman Filter: Applications to Forecasting and Rational Expectations Models. In: Bewley T (ed) Advances in Econometrics, Fifth World Congress, vol 1. Cambridge University Press, pp 245-283

Finicelli A (2007) House Price Developments and Fundamentals in the United States. Bank of Italy Occasional Paper No 7 doi:dx.doi.org/10.2139/ssrn.1014576

Roland G (2004) Understanding institutional change: Fast-moving and slow-moving institutions. Studies in Comparative International Development 38:109-131 doi: $10.1007 / \mathrm{BF} 02686330$ 
Girouard N, Kennedy M, van den Noord P, Andre C (2006) Recent house price developments: The role of fundamentals OECD Economics. Department Working Papers No 475 160 doi:10.1787/864035447847

Guirguis HS, Giannikos CI, Anderson RI (2005) The US housing market: Asset pricing forecasts using time varying coefficients. The Journal of Real Estate Finance and Economics 30:33-53 doi:10.1007/s11146-004-4830-z

Hansen BE (2001) The new econometrics of structural change: Dating breaks in U.S. labour productivity. Journal of Economic Perspectives 15:117-128 doi: 10.1257/jep.15.4.117

Hendry DF (1984) Econometric Modelling of House Prices in the United Kingdom. In: Hendry DF, Wallis KF (eds) Econometrics and Quantitative Economics. Basil Blackwell, Oxford, pp 211-252

Himmelberg C, Mayer C, Sinai T (2005) Assessing high house prices: Bubbles, fundamentals and misperceptions. Journal of Economic Perspectives 19:67-92 doi:10.1257/089533005775196769

Jackson DA (1993) Stopping rules in principal components analysis: A comparison of heuristical and statistical approaches. Ecology 74:2204-2214 doi:10.2307/1939574

Konzelmann SJ, Fovargue-Davies M, Schnyder G (2010) Varieties of Liberalism : AngloSaxon Capitalism in Crisis? Centre for Business Reasearch, University of Cambridge, Cambridge 
Li G, Wong KKF, Song H, Witt SF (2006) Tourism demand forecasting: A time varying parameter error correction model. Journal of Travel Research 45:175-185 doi:10.1177/0047287506291596

Lucas RE (1976) Econometric policy evaluation: A critique. Carnegie-Rochester Conference Series on Public Policy 1:19-46 doi:http://dx.doi.org/10.1016/S0167-2231(76)800036

Martin MF, Morrison WM (2008) China’s “Hot Money” Problems vol RS22921. CRS Report for Congress, https://www.fas.org/sgp/crs/row/RS22921.pdf. Accessed 25 June 2012

O’Connor P (2010) Changes to the Publication of Bank and Building Societies Statistics. Bank of England, Monetary and Financial Statistics

Pesaran MH, Timmermann A (2002) Market timing and return prediction under model instability. Journal of Empirical Finance 9:495-510 doi:http://dx.doi.org/10.1016/S0927-5398(02)00007-5

Quigley JM, Raphael S (2004) Is housing unaffordable? Why isn't it more affordable? Journal of Economic Perspectives 18:191-214 doi:10.1257/089533004773563494

Schwab RM (1982) Inflation expectations and the demand for housing. The American Economic Review 72:143-153 doi:10.2307/1808581 
Shiwakoti RK, Keasey K, Hudson R (2008) Comparative performance of UK mutual Building Societies and stock retail banks: Further evidence. Accounting and Finance 48:319-336 doi:10.1111/j.1467-629X.2007.00244.x

Stock JH, Watson MW (2006) Forecasting with Many Predictors. In: Elliott G, Granger CWJ, Timmermann A (eds) Handbook of Economic Forecasting, vol 1. 1 edn. Elsevier, pp 515-554. doi:http://dx.doi.org/10.1016/S1574-0706(05)01010-4

Tsay RS (2010) Analysis of Financial Time Series. Wiley, New Jersey

Van den Bossche FAM (2011) Fitting state space models with EViews. Journal of Statistical Software 41:1-16

Verardi V, Croux C (2008) Robust regression in Stata. The Stata Journal:1-23

Whelan K (2010) Global Imbalances and the Financial Crisis. European Parliament's Committee on Economic and Monetary Affairs, http://www.europarl.europa.eu/activities/committees/studies.do?language=EN, Accessed 17 August 2011

Wu Y (1997) Rational bubbles in the stock market: Accounting for the US stock-price volatility. Economic Inquiry 35:309-319 doi:10.1111/j.1465-7295.1997.tb01912.x

Xu XE, Chen T (2012) The effect of monetary policy on real estate price growth in China. Pacific-Basin Finance Journal 20:62-77 doi:http://dx.doi.org/10.1016/j.pacfin.2011.08.001 
Zivot E, Wang J (2006) Modeling Financial Time Series with S-PLUS®. Springer, New York 